\title{
A Simplified Preparation for Relating Cellular Events to Behavior: Contribution of LE and Unidentified Siphon Sensory Neurons to Mediation and Habituation of the Aplysia Gill- and Siphon- Withdrawal Reflex
}

\author{
Lina Frost, ${ }^{1}$ Saul W. Kaplan,, ${ }^{1}$ Tracey E. Cohen, ${ }^{1}$ Victor Henzi, ${ }^{1}$ Eric R. Kandel, ${ }^{1,2,3}$ and Robert D. Hawkins ${ }^{1,2}$ \\ ${ }^{1}$ Center for Neurobiology and Behavior, College of Physicians and Surgeons of Columbia University, ${ }^{2}$ New York State \\ Psychiatric Institute, and ${ }^{3}$ Howard Hughes Medical Institute, New York, New York 10032
}

\begin{abstract}
We have begun to analyze several elementary forms of learning in a simple preparation consisting of the isolated mantle organs and abdominal ganglion of Aplysia. Previous studies suggested that plasticity at siphon sensory neuron synapses contributes to habituation and dishabituation of the gill- and siphonwithdrawal reflex in this preparation. We next wished to identify the sensory neurons that participate in the reflex and examine their plasticity more directly. To investigate the contribution of the LE siphon mechanosensory cells, we recorded from them and gill or siphon motor neurons during the same siphon stimulation that has been used in behavioral experiments in this preparation. Our results indicate that the LE cells make a substantial contribution to the evoked response in the motor neurons under these conditions, but they suggest that other as yet unidentified siphon sensory neurons with lower thresholds and shorter latencies also contribute. In addition, we find that
\end{abstract}

homosynaptic depression of monosynaptic postsynaptic potentials (PSPs) from LE sensory cells makes an important contribution to habituation of the response in the motor neurons. To investigate plasticity of PSPs from the unidentified sensory neurons, we recorded the PSP that was produced in a motor neuron by water-movement stimulation of the siphon, which does not cause firing of LE cells. Our results suggest that PSPs from the unidentified sensory neurons and the LE neurons undergo similar plasticity during habituation and dishabituation training. These results support the idea that plasticity at synapses of both LE and unidentified sensory neurons contributes to habituation and dishabituation of the reflex response in this preparation.

Key words: Aplysia; gill-withdrawal reflex; siphon; sensory neurons; latency; threshold; habituation; dishabituation; learning
One of the great attractions of studying the nervous systems of simple organisms like Aplysia is the possibility of relating the activity of single identified neurons to behavior. Toward that end, we have developed a simplified preparation consisting of the isolated mantle organs and abdominal ganglion of Aplysia with which it is relatively easy to record the activity of individual neurons during behavior. Although this preparation contains only 2000 neurons, it undergoes several simple forms of learning, including habituation, dishabituation, sensitization, classical conditioning, and second-order conditioning (Cohen et al., 1991, 1997; Hawkins et al., 1993). Initial cellular studies suggested that plasticity at siphon sensory neuron synapses contributes to habituation and dishabituation of the gill- and siphon-withdrawal reflex in this preparation (Cohen et al., 1997). To carry the analysis further, we needed to identify the sensory neurons that participate in the reflex. Previous studies have indicated that the LE siphon mechanosensory cells play a key role in the reflex and its plasticity (Castellucci et al., 1970; Byrne et al., 1974, 1978a,b; Castellucci and Kandel, 1974, 1976), but in those studies the cellular and

Received Sept. 20, 1996; revised Jan. 2, 1997; accepted Jan. 31, 1997.

This work was supported by grants from the National Institute of Mental Health (MH26212) and the Howard Hughes Medical Institute. We thank J. Koester and I. Kupfermann for their comments, A. Krawetz, H. Ayers, and I. Trumpet for typing this manuscript, and C. Lam and S. Mack for preparing the figures.

Correspondence should be addressed to Dr. Robert D. Hawkins, Center for Neurobiology and Behavior, Columbia University, 722 West 168th Street, New York, NY 10032.

Copyright (C) 1997 Society for Neuroscience $\quad 0270-6474 / 97 / 172900-14 \$ 05.00 / 0$ behavioral experiments were generally carried out in different preparations with different stimulation parameters, etc. Therefore, we have investigated the contribution of the LE cells by recording from them and gill or siphon motor neurons in the simplified preparation, with the same siphon stimulation that has been used in behavioral experiments on habituation, dishabituation, sensitization, and classical conditioning of the reflex (Cohen et al., 1991, 1997; Hawkins et al., 1993). Our results indicate that the LE cells make a substantial contribution to the evoked response in the motor neurons under these conditions, but they suggest that other as yet unidentified siphon sensory neurons with lower thresholds and shorter latencies also contribute. We also examined plasticity of postsynaptic potentials (PSPs) from the LE cells and the unidentified sensory cells and found that they undergo similar depression and facilitation during habituation and dishabituation training in this preparation.

Some of these results have been published previously in abstract form (Cohen et al., 1991; Kaplan et al., 1993, 1994; Hawkins and Frost, 1995).

\section{MATERIALS AND METHODS}

Adult Aplysia californica weighing 75-250 gm were obtained from either Marinus (Long Beach, CA) or the Howard Hughes Mariculture Facility (Miami, FL). The experimental preparation was the same as in the preceding paper (Cohen et al., 1997). The siphon was stimulated with three different mechanical devices. The first stimulator was a tapper driven by a solenoid (Guardian Electric, Chicago, IL) that pulled against a spring. This stimulator was similar to ones used in previous studies (Goldberg and Lukowiak, 1984), except that the tapper was connected to 
the solenoid directly, rather than through a lever arm. The tip of the tapper was soft plastic, $2 \mathrm{~mm}$ in diameter, and the tap duration was 80 msec. The force of the taps was adjusted by varying the initial distance between the tip of the tapper and the siphon, with longer distances producing weaker taps. In some cases, the tapper never actually touched the siphon at all, and the stimulus was presumably the water movement produced by the tapper. The second was a stimulator with feedback control of the force of the tap identical to the one used by Byrne et al. $(1974,1978 \mathrm{a}, \mathrm{b})$. The tip of the tapper was stainless steel, $0.5 \mathrm{~mm}$ in diameter, and the tap duration was either 50 or $500 \mathrm{msec}$. The third was a controlled force stimulator identical to the one used by Cohen et al. (1997). The tip of the tapper was stainless steel, $1.5 \mathrm{~mm}$ in diameter, and the tap duration was $500 \mathrm{msec}$. The stimulators were calibrated against a strain gauge transducer (Grass Instruments, Quincy, MA). The habituation and dishabituation procedures were also the same as in the preceding paper (Cohen et al., 1997). When serotonin was used for dishabituation, it was applied to the ganglion through the perfusion system at a concentration of $10 \mu \mathrm{M}$ in " $\mathrm{Hi} \mathrm{Ca}^{2+}$, $\mathrm{Hi} \mathrm{Mg}{ }^{2+}$ " seawater (Cohen et al., 1997).

An LE siphon mechanosensory neuron, identified by its electrophysiological properties and response to siphon stimulation (Byrne et al., 1974), and a gill or siphon motor neuron (L7, LDG, or LFS) (Frazier et al., 1967; Kupfermann et al., 1974; Frost et al., 1988) were impaled with single- or double-barreled glass microelectrodes filled with $2.5 \mathrm{M} \mathrm{KCl}$. It is easier to record from L7 or LFS cells at the same time as LE cells because they can be visualized from the same side of the ganglion; however, LDG is more behaviorally relevant because it mediates most of the gill-withdrawal reflex in this preparation (Cohen et al., 1997). For these reasons we used L7 or LFS in our initial experiments on the possible existence of another class of sensory cells, and LDG in some or all of our subsequent experiments on the relative contributions and plasticity of PSPs from the sensory cells during behavioral training. In some experiments the motor neuron was hyperpolarized $\sim 30 \mathrm{mV}$ below resting potential to prevent firing. On each trial we measured the spikes produced in the LE sensory neuron and the spikes or PSP produced in the motor neuron by siphon stimulation. In some experiments we also fired an action potential in the LE neuron with intracellular current injection through a bridge-balance circuit and measured the monosynaptic PSP produced in the motor neuron.

\section{RESULTS}

\section{Participation of LE and unidentified siphon sensory neurons in the evoked response in the motor neurons} The solenoid stimulator

In the first series of experiments we stimulated the siphon with a solenoid-driven tapper that was positioned in the receptive field of an LE sensory neuron. Stimulus intensity was adjusted by varying the distance between the tip of the tapper and the siphon before the tap. The distance was initially set at a large value and then progressively decreased (increasing intensity) at $1 \mathrm{~min}$ intervals until responses were produced in the sensory neuron, a motor neuron, and the gill.

As illustrated in the example in Figure $1 A$ and the group data in Figure $1 B$, the LE cell always fired action potentials if the tapper moved far enough to touch the siphon, but never fired action potentials if the tapper clearly did not touch the siphon (32 LE cells in 21 preparations). The tapper travel distance was between 2 and $3 \mathrm{~mm}$; LE cells fired action potentials when the distance between the tapper and the siphon before the tap was in that range $(\bar{X}=2.67 \pm 0.03 \mathrm{~mm})$.

The distance at which the tapper first produced a gill withdrawal was always greater (lower intensity) than the distance at which it produced firing of an LE cell. On average, the difference between the "threshold" for producing a gill withdrawal and firing of an LE cell in the same preparation was $2.23 \pm 0.57 \mathrm{~mm}(n=$ $\left.32 ; t_{(31)}=3.91 ; p<0.01\right)$. Surprisingly, in 10 of 21 preparations the tapper produced a gill withdrawal when it did not actually touch the siphon (initial distance between the tapper and the siphon $>3 \mathrm{~mm}$ ). Moreover, the tapper always produced some

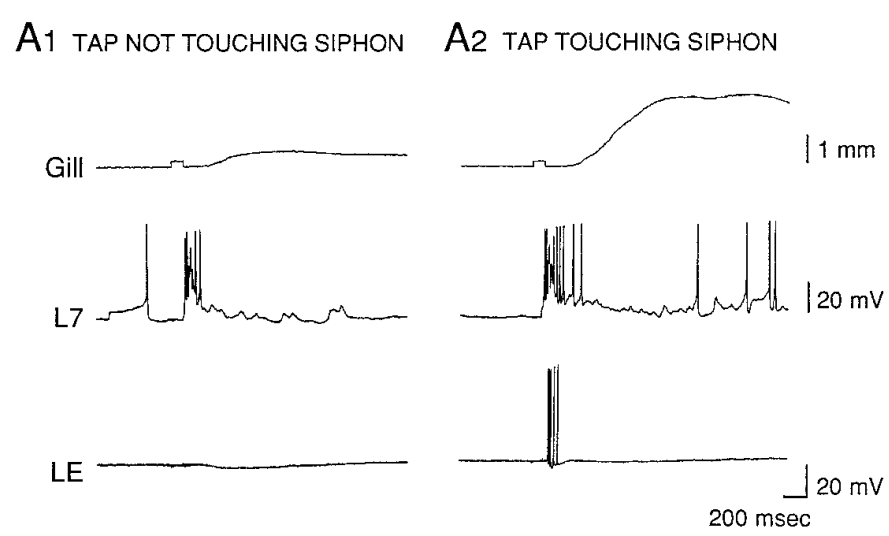

B

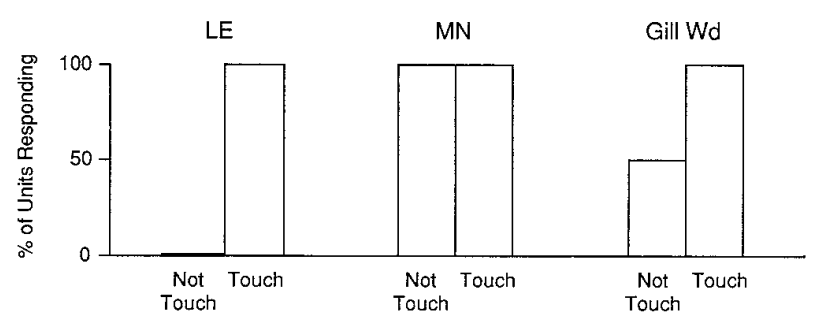

Figure 1. Simultaneously recorded firing of an LE sensory neuron, a gill or siphon motor neuron (L7 or LFS), and gill withdrawal in response to stimulation of the siphon with a solenoid-driven tapper. $A$, Records from a representative experiment showing the responses to taps that either did not $(A 1)$ or did $(A 2)$ touch the siphon. The square pulse in the gill record indicates the time of the siphon tap. $B$, Percentage of cases in which there was firing of an LE sensory neuron $(L E)$, firing of a motor neuron $(M N)$, or gill withdrawal $($ Gill $W d$ ) in response to siphon taps that either did not or did touch the siphon. Preparations were included in these experiments only if direct stimulation of the siphon produced a measurable gill withdrawal.

firing of the motor neuron when it did not touch the siphon (21 of 21 motor neurons; $\chi^{2}=49.08 ; p<0.01$, compared with the LE sensory neurons).

When the tap did touch the siphon it produced firing of the LE sensory neuron, an increase in firing of the motor neuron, and a larger gill withdrawal (Fig. 1). The beginning of the response in the motor neuron always had a shorter latency than the first spike in the LE neuron, however (21 of 21 motor neurons) (Fig. 2). On average, the difference between the latencies of the onsets of the responses in an LE sensory neuron and a motor neuron in the same preparation was $60.2 \pm 5.3 \mathrm{msec}\left(t_{(20)}=11.36 ; p<0.01\right)$.

These results indicate that the LE sensory neurons participate in the response in the motor neuron and the behavioral response when the tapper touches the siphon; however, they also suggest that there is another as yet unidentified group of sensory neurons that respond when the tapper does not touch the siphon, and that produce responses in the motor neuron with shorter latencies than the LE cells when the tapper does touch the siphon. Alternatively, there exists a subset of LE cells with lower thresholds and shorter latencies that we did not sample. Presumably, the threshold and latency of the synaptic response in the motor neurons are determined by the first sensory cells to respond, rather than the average sensory cell response. We sampled a large number of LE cells (more than 70 in this paper), however, without finding an exception, and we made a deliberate effort to sample LE cells in different locations in the ganglion (including those below the surface layer). Another possibility is that the sensory cells we 
A
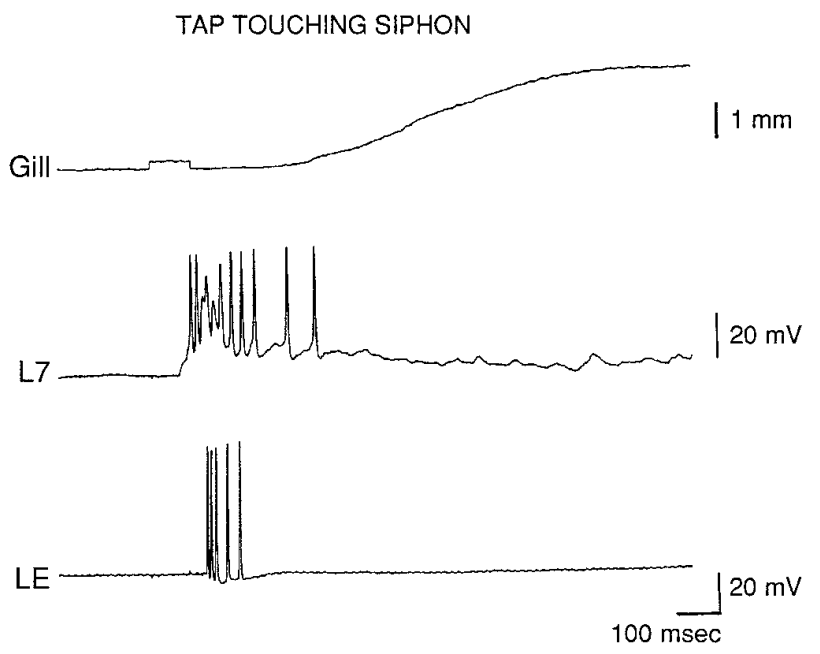

B

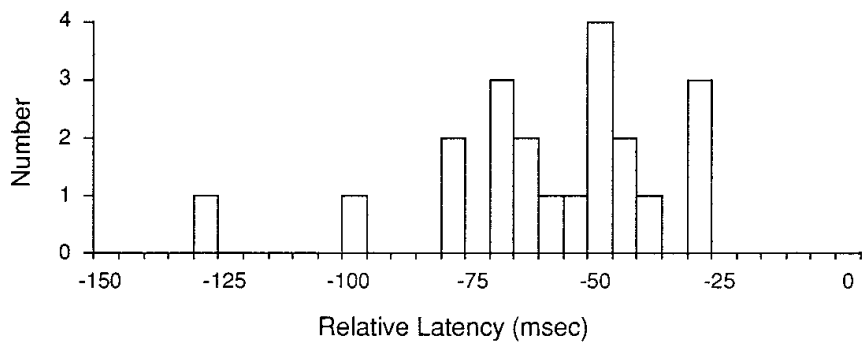

Figure 2. Comparison of the latencies of the PSP in a motor neuron and the first spike in an LE sensory neuron in response to stimulation of the siphon with a solenoid-drive tapper. $A$, Records from the same trial as Figure $1 A 2$ with an expanded time scale. $B$, Histogram of the differences between the latencies of the PSP in a motor neuron and the first spike in an LE sensory neuron in the same preparation $(n=21)$. Negative numbers mean that the PSP had a shorter latency.

sampled had higher thresholds and longer latencies than normal because they were damaged by the intracellular electrode. This seems unlikely, because the action potentials are generated in the periphery, far from the recording site. To examine this possibility, however, we performed four additional experiments in which we recorded action potentials in the LE cell with an extracellular electrode pressed against the cell body, and we obtained similar results (data not shown).

It is not clear what the nature of the stimulus is when the tapper does not touch the siphon: it could be either local water movement, more widespread water movement, or vibration of the table caused by the tapper. In preliminary experiments, we found that if we first habituated the gill-withdrawal response by repeated stimulation we could still produce a response if we moved the tapper to a different spot on the siphon, suggesting that the effective stimulus is a fairly localized water movement.

\section{The Byrne stimulator}

It was possible that the results we obtained in the first series of experiments were peculiar to the device that we used to stimulate the siphon. We therefore conducted a second series of experiments with a feedback-controlled mechanical stimulator identical to the one used by Byrne et al. (1974, 1978a,b). This provided a better-defined stimulus and allowed us to produce controlledforce stimuli down to $0.5 \mathrm{gm} / \mathrm{mm}^{2}$, so that we could also examine thresholds.

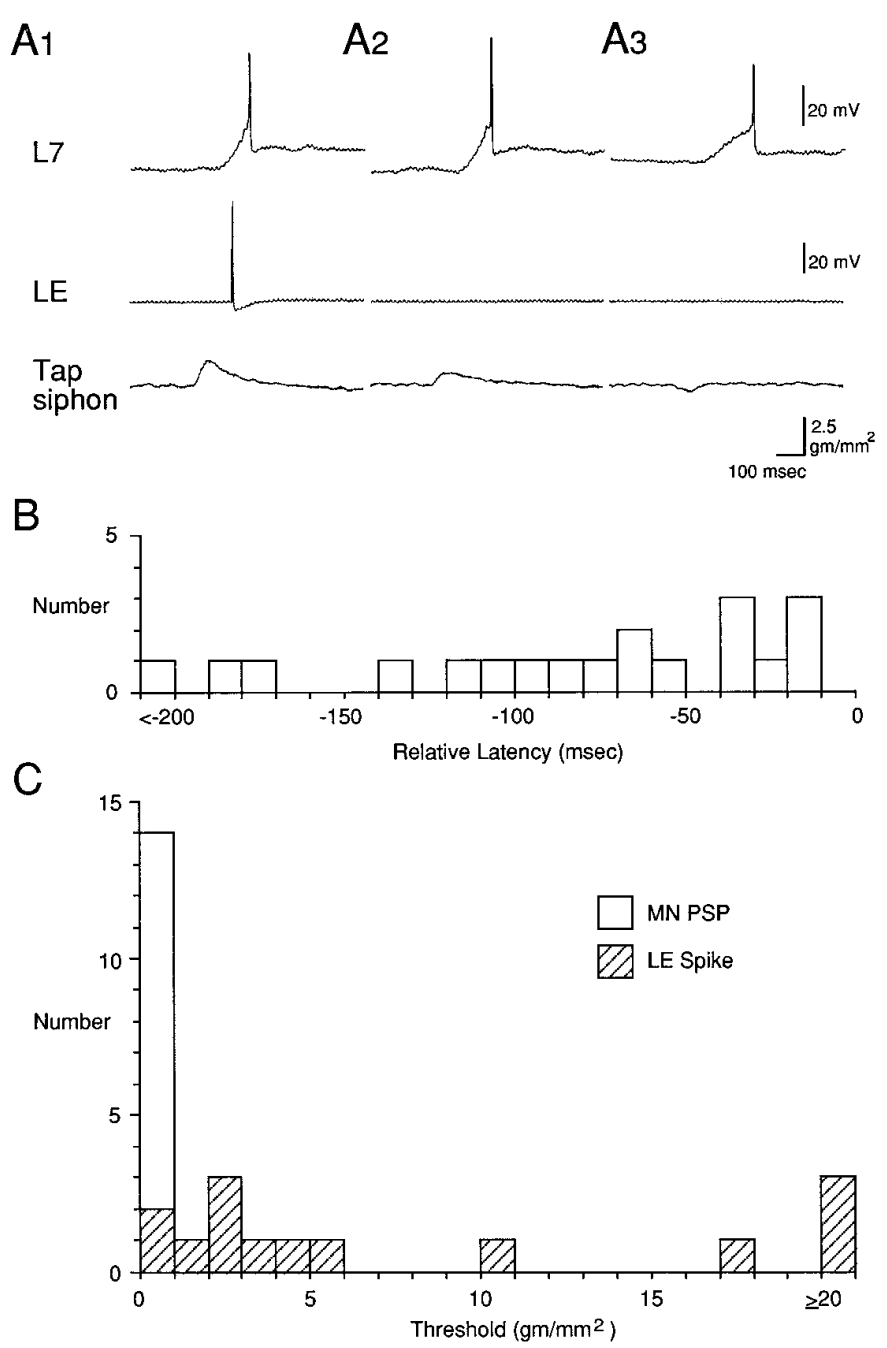

Figure 3. Relative latencies and thresholds for the PSP in a motor neuron and the first spike in an LE sensory neuron in response to controlled-force stimulation of the siphon with a stimulator identical to the one used by Byrne et al. (1974, 1978a,b). $A$, Records from a representative experiment with a $50 \mathrm{msec}$ tap that was either above the threshold of the LE cell $(A 1)$, below the LE threshold $(A 2)$, or did not appear to touch the siphon at all, as indicated by a downward deflection in the stimulator transducer record (A3). B, Histogram of the differences between the latencies of the PSP in a motor neuron and the first spike in an LE sensory neuron in the same preparation $(n=19)$. $C$, Histogram of the threshold for producing a PSP in a motor neuron (open bar) and a spike in an LE sensory neuron (hatched bars) in the same preparation $(n=14)$.

We stimulated the siphon at 1 min intervals with ascending and descending intensities until we found the thresholds for producing a spike in an LE neuron and a PSP in a motor neuron recorded simultaneously. Tap duration was either $50 \mathrm{msec}(n=9)$ or 500 msec $(n=10)$. The latency and threshold of the first LE spike were similar with $50 \mathrm{msec}$ and $500 \mathrm{msec}$ taps, and the data have been pooled. As shown in the example in Figure $3 A 1$ and the histogram in Figure $3 B$, the first spike in the LE neuron always had a longer latency than the PSP in the motor neuron $(n=19 \mathrm{LE}$ cells in 17 preparations; average difference $=88.8 \pm 20.2 \mathrm{msec}$; $\left.t_{(18)}=4.40 ; p<0.01\right)$, confirming the results obtained with the other stimulator. Moreover, when the tap was below the threshold for producing a spike in the LE cell, it still produced a PSP in the motor cell (Fig. 3A2). As shown in the histogram in Figure $3 C$, the median threshold for producing a spike in an LE cell was 3.8 
A

L7

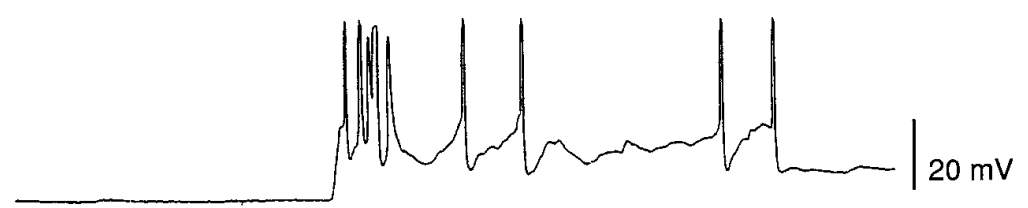

LE

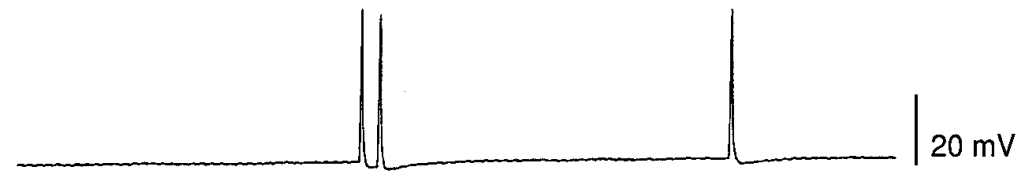

TAP SIPHON

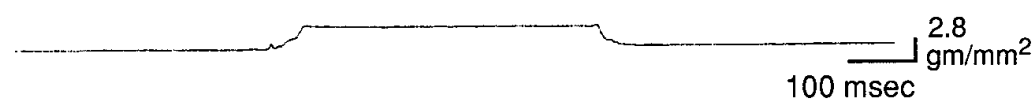

B

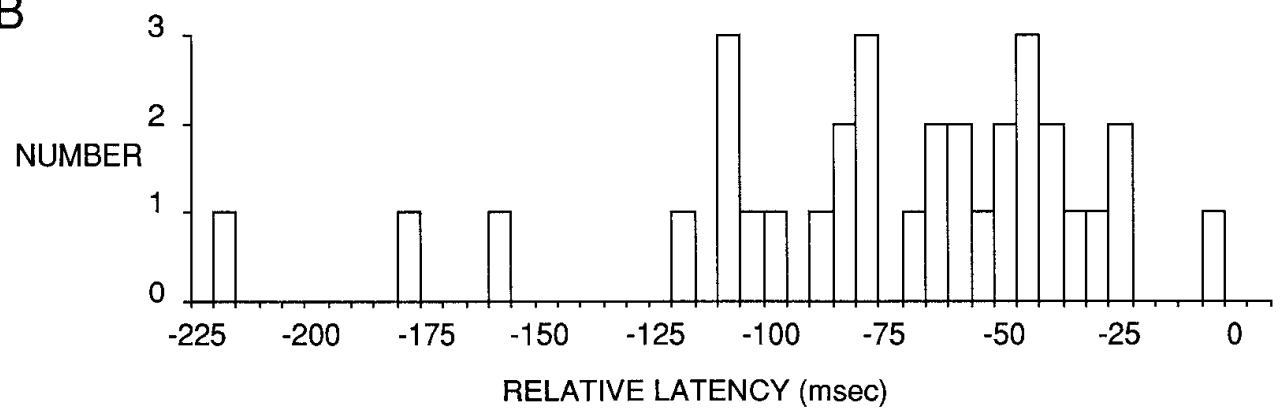

Figure 4. Comparison of the latencies of the PSP in a motor neuron and the first spike in an LE sensory neuron in response to controlled force stimulation of the siphon with a stimulator identical to the one used for behavioral experiments with this preparation (Cohen et al., 1991, 1997; Hawkins et al., 1993). $A$, Records from a representative experiment. $B$, Histogram of the differences between the latencies of the PSP in a motor neuron and the first spike in an LE sensory neuron in the same preparation $(n=33)$. $\mathrm{gm} / \mathrm{mm}^{2}(n=14)$, whereas the threshold for producing a PSP in a simultaneously recorded motor cell was always less than the weakest tap we could produce. In fact, in some cases with a 50 msec tap, when the tapper did not seem to touch the siphon at all (as indicated by a downward deflection in the stimulator transducer record) (Fig. 3A3), there was still always a PSP in the motor cell, confirming the results of the first series of experiments (Fig. 1). This was also true for one LE cell (Fig. 3C), but in that case reducing the stimulator setting caused the LE cell to stop responding, suggesting that the LE cell fired when the tapper just touched the siphon.

\section{The stimulator used in behavioral experiments with this preparation}

The results of the first two series of experiments indicate that the LE sensory neurons participate in the evoked response in the motor neurons with moderate intensity stimuli, but that other, unidentified sensory neurons with lower thresholds and shorter latencies also participate. These results raise the question of the relative contributions of the two types of sensory neurons. As shown in Figures $1 A 1$ and $3 A 3$, it is possible to produce stimulus conditions (weak siphon stimuli of short duration) under which the LE neurons do not contribute at all. What about the conditions that have been used for behavioral experiments with this preparation? To answer that question, we conducted a third series of experiments with a feedback-controlled mechanical stimulator identical to the one used for studies of plasticity of the reflex (Cohen et al., 1991, 1997; Hawkins et al., 1993), with which we could produce controlled-force stimuli down to $2.8 \mathrm{gm} / \mathrm{mm}^{2}$.

As shown in the example in Figure $4 A$ and the group data in Figure $4 B$, the beginning of the PSP in the motor cell again always had a shorter latency than the first spike in the LE cell (33 LE cells in 27 preparations). On average, the difference between the latencies of the onsets of the responses in the LE cell and the motor cell was $77.0 \pm 8.1 \mathrm{msec}\left(t_{(32)}=9.51 ; p<0.01\right)$. This difference did not depend on whether the motor cell was L7 $(n=14)$ or LFS $(n=13)$. The data in Figure $4 B$ are all from the first test of the pair of cells after a rest of at least $15 \mathrm{~min}$ (average intensity $=4.8$ $\mathrm{gm} / \mathrm{mm}^{2}$ ). In most preparations we retested the same cells with a series of different intensities at 1 min intervals. As shown in Figure $5 A 1$, varying tap intensity had no effect on the difference between the latencies of the onsets of the responses in the two cells. In some preparations we repeatedly tested the same cells at the same tap intensity (average $=6.2 \mathrm{gm} / \mathrm{mm}^{2}$ ) at $15-60 \mathrm{sec}$ intervals. As shown in Figure $5 A 2$, repeated testing also had no effect on the difference between the onsets of the responses in the two cells $(n=9)$. Thus, under all conditions that we examined, the beginning of the PSP in the motor cell had a shorter latency than the first spike in the LE cell. These results agree with the results obtained with the other stimulators, and they suggest that in addition to the LE cells, other as yet unidentified sensory cells participate in the reflex response.

In these experiments we also counted the number of spikes that the tap produced in the LE cells. As shown in Figure 5B1, increasing tap intensity from 2.8 to $23 \mathrm{gm} / \mathrm{mm}^{2}$ caused a monotonic increase in the number of spikes in the LE cell $\left(F_{(4,45)}=\right.$ $85.72 ; p<0.01)$, with a less rapid rise above $10 \mathrm{gm} / \mathrm{mm}^{2}$. There was brisk firing of the LE cells in the range used in the behavioral experiments, which was usually around $20 \mathrm{gm} / \mathrm{mm}^{2}$ (Cohen et al., 1991, 1997; Hawkins et al., 1993). These results are quantitatively similar to those of Byrne et al. (1978a) if one takes into account 
A1

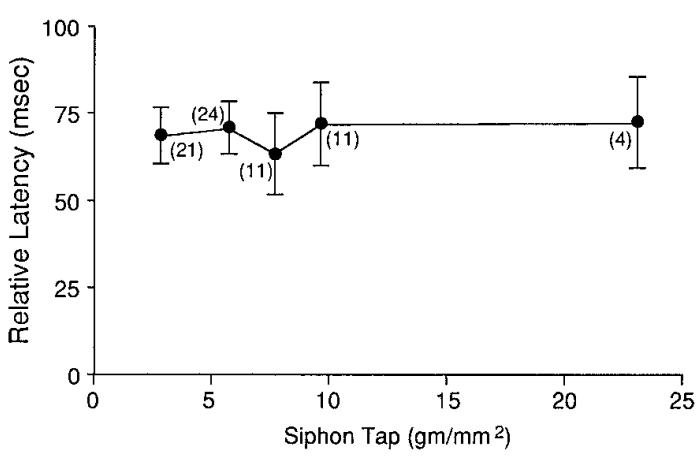

Figure 5. Relative latencies and number of spikes in LE neurons as a function of stimulus intensity and repeated testing. $A$, Comparison of the latencies of the first spike in an LE cell and the PSP in a motor cell in response to controlledforce stimulation of the siphon as a function of stimulus intensity $(A 1)$ or repeated testing $(A 2)$. $B$, Number of spikes in the sensory neuron as a function of stimulus intensity $(B 1)$ or repeated testing (B2). The points represent the means, the vertical bars represent the SEM, and the numbers in parentheses represent the $n$ at each intensity.
B1

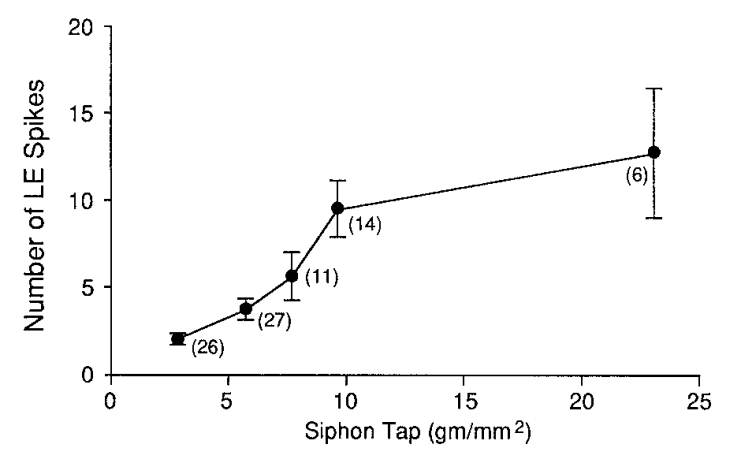

B2

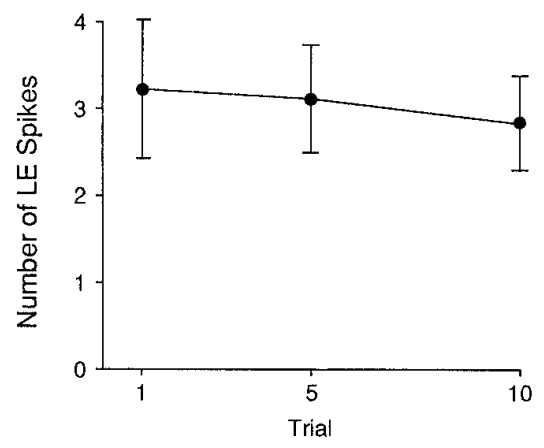

the diameter of the tapper. By contrast, repeated testing for up to 10 trials had no significant effect on the number of spikes in the LE cell (Fig. 5B2).

The observation that the latency of the PSP in the motor cell is always shorter than the latency of the first spike in an LE cell suggests that other sensory cells contribute to the earliest part of the motor cell response. The LE cells, however, fire at an appropriate time to contribute to most of the response in the motor cell (Figs. 2, 4). This relationship is quantified in Figure 6, which shows histograms of the average pattern of firing in an LE cell and a simultaneously recorded motor cell in response to weak $(<8$ $\left.\mathrm{gm} / \mathrm{mm}^{2}\right)$ and stronger $\left(>8 \mathrm{gm} / \mathrm{mm}^{2}\right) 500 \mathrm{msec}$ taps to the siphon.

The first spikes in the LE cells occur 50-100 msec after the start
A2

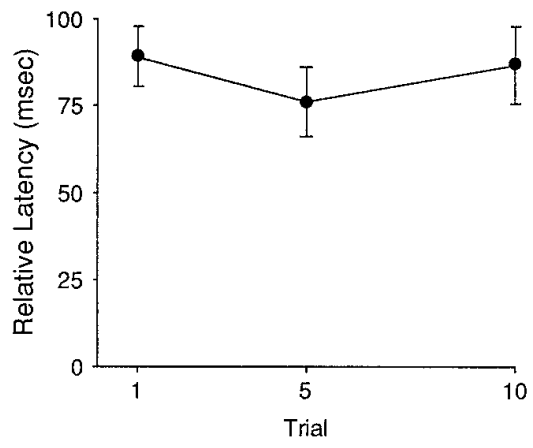

of the tap. The response peaks $\sim 150$ msec after the start of the tap and then declines to sustained lower frequency firing that ends $\sim 200 \mathrm{msec}$ after the end of the tap. Stronger taps produce more spikes in the LE cells, in agreement with the results shown in Figure $5 B 1$. In addition, stronger taps produce a relatively larger sustained response during the tap, so that the overall pattern of firing is somewhat different with weak and stronger taps $\left(\chi^{2}=\right.$ 37.72; $p<0.01$, comparing the fraction of total spikes in each 50 msec interval for weak and stronger taps).

The onset and the peak of the response both occur $\sim 50 \mathrm{msec}$ earlier in the motor neurons than in the LE neurons, suggesting that other sensory neurons contribute to that part of the response. The motor neuron response is also more prolonged, and there is
Weak Tap

Figure 6. Average pattern of firing in an LE neuron $(L E)$ and a motor neuron $(M N)$ in response to controlled-force stimulation of the siphon of weak $(2.8-$ $\left.7.8 \mathrm{gm} / \mathrm{mm}^{2}\right)$ or stronger $\left(9.7-23.0 \mathrm{gm} / \mathrm{mm}^{2}\right)$ intensity. The average spike frequency in each $50 \mathrm{msec}$ interval was calculated as the total number of spikes in that interval divided by $(0.05 \times N)$. Time 0.0 is the start of the tap. The approximate duration of the plateau of the tap is indicated by the horizontal line below the $x$-axis. Rested preparations were tested with a weak tap; some of those preparations were then retested with stronger taps.
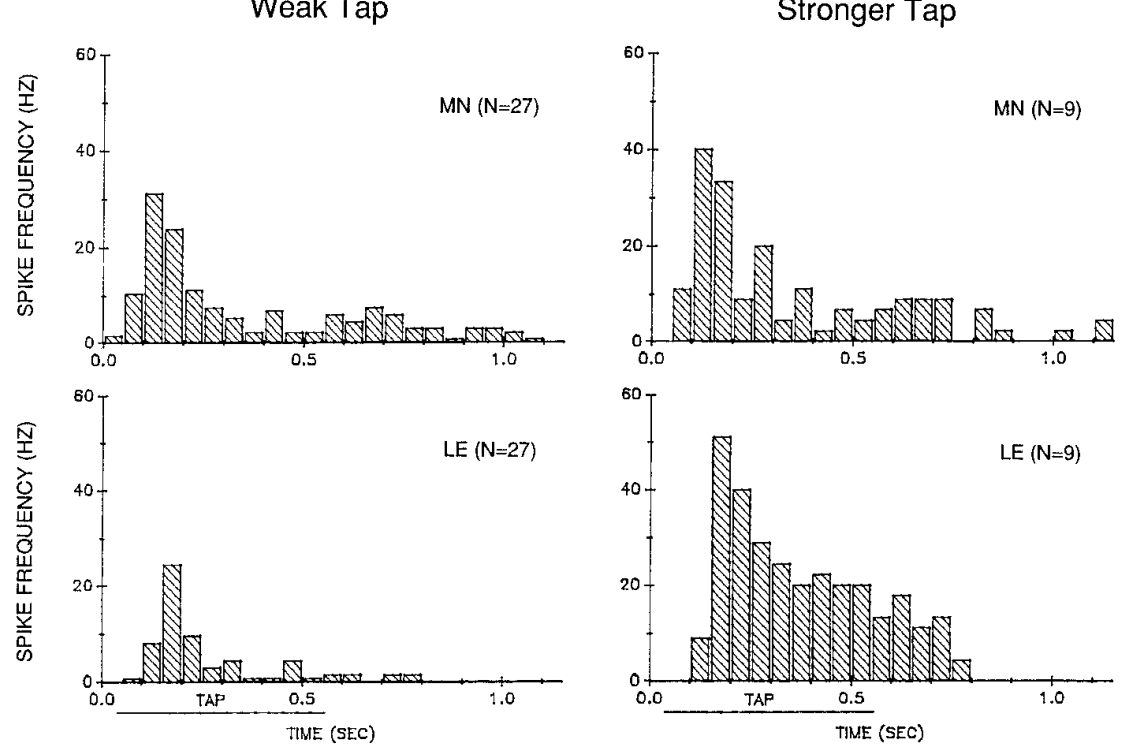


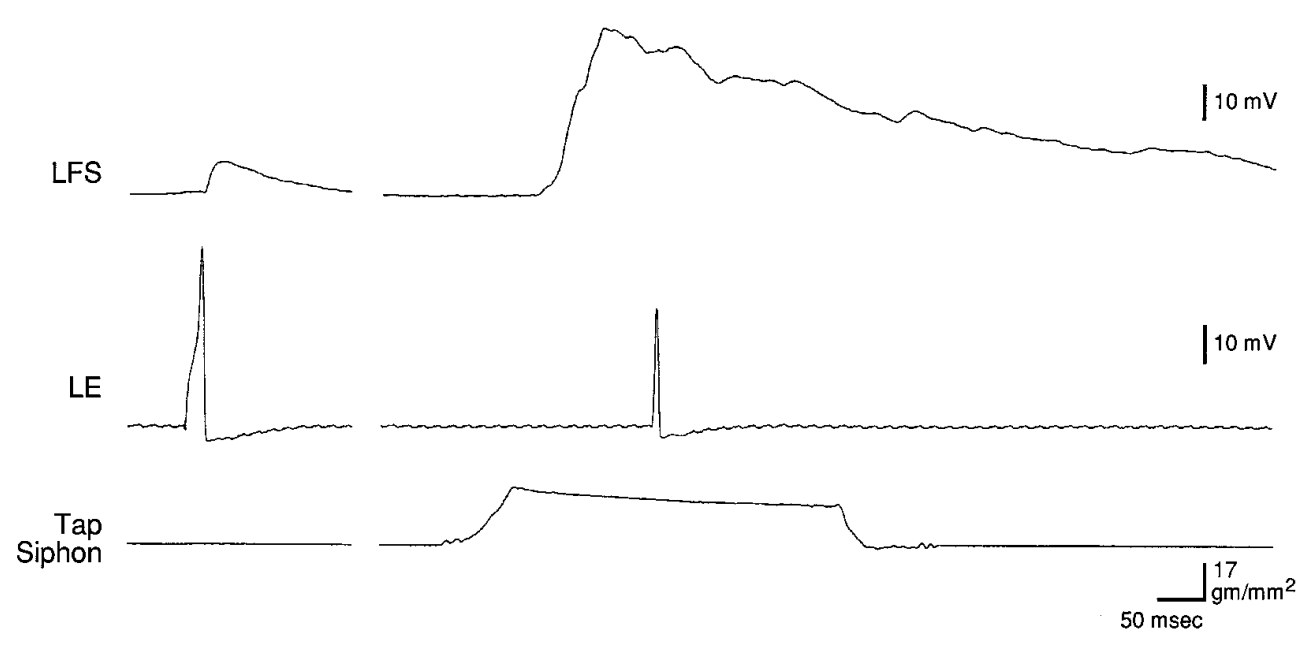

Figure 7. Example of the monosynaptic PSP produced in a motor neuron by intracellular stimulation of an LE sensory neuron and the complex PSP produced by controlled-force stimulation of the siphon, measured $\sim 10 \mathrm{sec}$ apart under identical conditions. a small but noticeable second peak of firing in the motor neurons around the offset of the tap that is not evident in the LE neurons. The overall pattern of firing of the motor neurons, however, is basically similar to that of the LE neurons, indicating that the LE neurons contribute to most of the motor neuron response.

\section{Comparison of the monosynaptic PSP from an LE cell and the complex PSP}

As another way of assessing the contribution of the LE neurons to the motor neuron response, we compared the monosynaptic PSP produced in a motor neuron by intracellular stimulation of an LE sensory neuron and the complex PSP produced by mechanical stimulation of the siphon, measured $\sim 10 \mathrm{sec}$ apart under identical conditions (Fig. 7). On average, the amplitude of the monosynaptic PSP produced by a single spike in an LE cell was $35.2 \pm$ $5.4 \%$ of the amplitude of the complex PSP, and the area of the monosynaptic PSP was $6.4 \pm 1.5 \%$ of the area of the complex PSP $(n=19)$. The results were similar whether the motor neuron was LFS or LDG $\left(n=15\right.$ and $4 ; t_{(17)}=0.26$ for amplitude and 0.22 for area; $p \geq 0.80$ ) and therefore have been pooled. In these experiments, when the tap was within the receptive field of an LE cell, it fired on average $2.8 \pm 0.6$ spikes during the tap $(n=16)$. This number is smaller than in the experiments illustrated in Figures 5 and 6 , perhaps because we did not make any effort to position the tapper in the center of the receptive field of the LE cell. By multiplying the area of the monosynaptic PSP and the number of spikes in an LE cell, the monosynaptic PSPs from a single LE cell could contribute as much as $18 \%$ of the area of the complex PSP if they added linearly.

\section{Plasticity of the complex PSP and firing of LE cells during habituation training}

The data shown in Figure 7 are from the first test after a rest of at least $30 \mathrm{~min}$. Figure 8 shows histograms of the average pattern of firing of an LE cell and the complex PSP in a motor cell in experiments in which we were able to hold the cells during five trials of habituation training. On average, the complex PSP had the same four components that we have described previously (Cohen et al., 1997): a peak near the onset of the tap, a smaller plateau during the remainder of the tap, a second peak around the offset of the tap, and a gradual decline after the tap. The pattern was similar whether the motor neuron was LFS $(n=9)$ or LDG $(n=8)$. The average pattern of firing of the LE cells was similar to that shown in Figure 6. Peak firing of the LE cells occurred around the initial peak of the complex PSP, and the pattern of firing of the LE cells was similar to the pattern of the complex PSP during the tap. There was relatively little firing of LE cells after the tap, however, whereas there was a second peak followed by a gradual decline in the complex PSP. These results suggest that the LE cells contribute to most of the complex PSP during the tap but make little direct contribution to the PSP after the tap.

After five trials of habituation training, there was a significant decrease in the total area of the complex PSP $\left(t_{(16)}=2.99 ; p<\right.$ 0.01) (Fig. 9). Again, as described previously (Cohen et al., 1997), there was little change in the initial peak of the PSP, and an approximately equal decrease in the remaining three components of the PSP (Fig. 8). These results were similar whether the motor neuron was LFS or LDG $\left(t_{(15)}=0.44 ; p=0.67\right)$, and therefore they have been pooled. In agreement with the results shown in Figure $5 B 2$, after habituation training there was no significant change in the number of spikes produced by the tap in the LE cells (Fig. 9), and also no significant change in the pattern of firing of the LE cells (Fig. 8). These results suggest that habituation in this preparation is not attributable to a change in firing of the LE cells, in agreement with previous studies (Byrne et al., 1978a).

\section{Plasticity of the monosynaptic PSP from an LE cell during habituation training}

We tested the monosynaptic PSP from an LE cell to the motor cell before the first and fifth trials of habituation training. As shown in Figure 9, when the siphon tap was within the receptive field of an LE cell ("On-field"), the monosynaptic PSP from that LE cell underwent significant depression during habituation training $(\bar{X}$ on trial $5=40.8 \pm 8.5 \%$ of trial $\left.1 ; n=10 ; t_{(9)}=6.98 ; p<0.01\right)$. By contrast, when the siphon tap was outside the receptive field of an LE cell ("Off-field"), the monosynaptic PSP did not undergo significant depression $(\bar{X}=95.1 \pm 9.5 \%$ of trial $1 ; n=7)$. Depression of monosynaptic PSPs from on-field LE cells was significantly greater than that of PSPs from off-field LE cells $\left(t_{(15)}\right.$ $=4.21 ; p<0.01)$. The results were similar whether the motor neuron was LFS or LDG $\left(n=12\right.$ and $5 ; F_{(1,13)}$ for interaction $=$ $2.06 ; p=0.18$ ), and they therefore have been pooled.

These results suggest that homosynaptic depression of monosynaptic PSPs from LE cells contributes to depression of the complex PSP during habituation training. The fact that the monosynaptic PSP undergoes greater depression than the complex PSP suggests that other components of the complex PSP do not decrease during habituation. Because the initial peak of the complex 
A

Trial 1
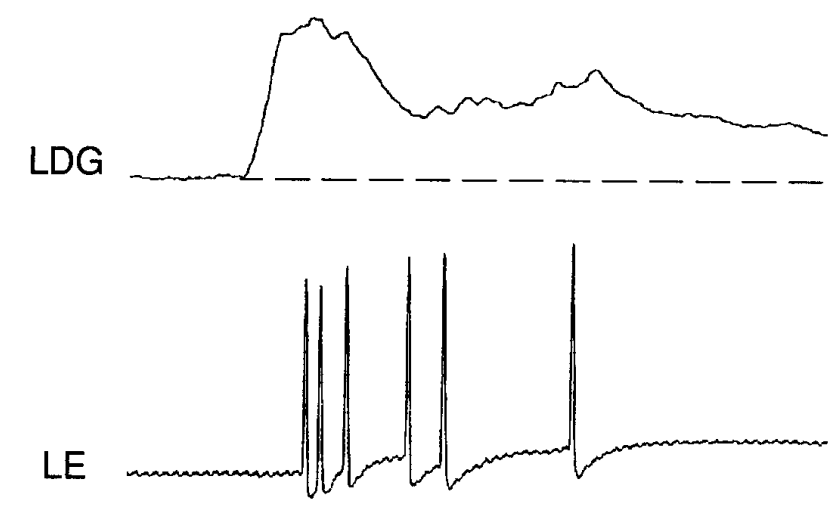

Tap Siphon

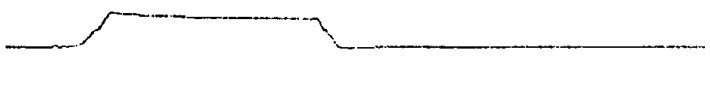

Trial 5
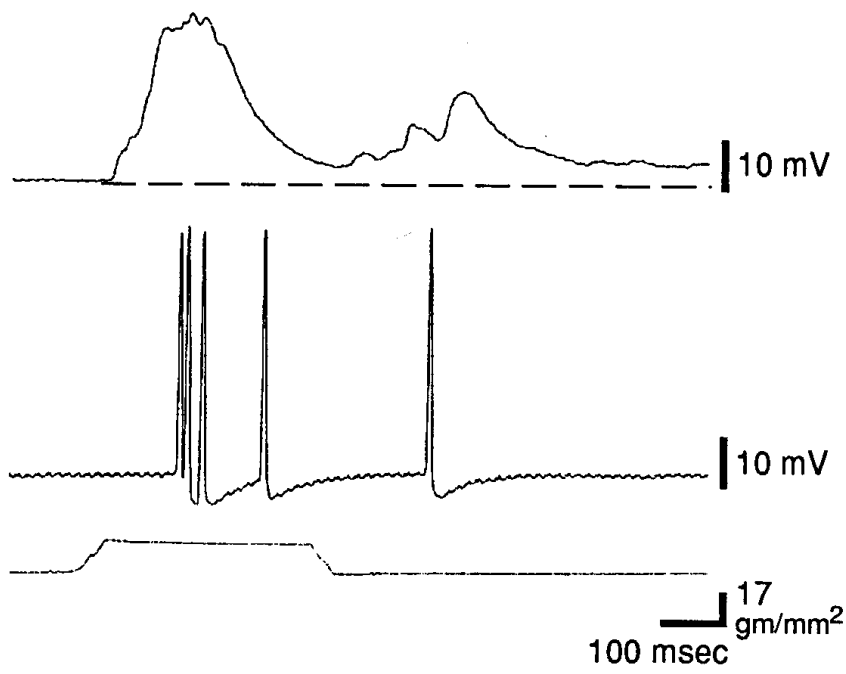

Trial 5
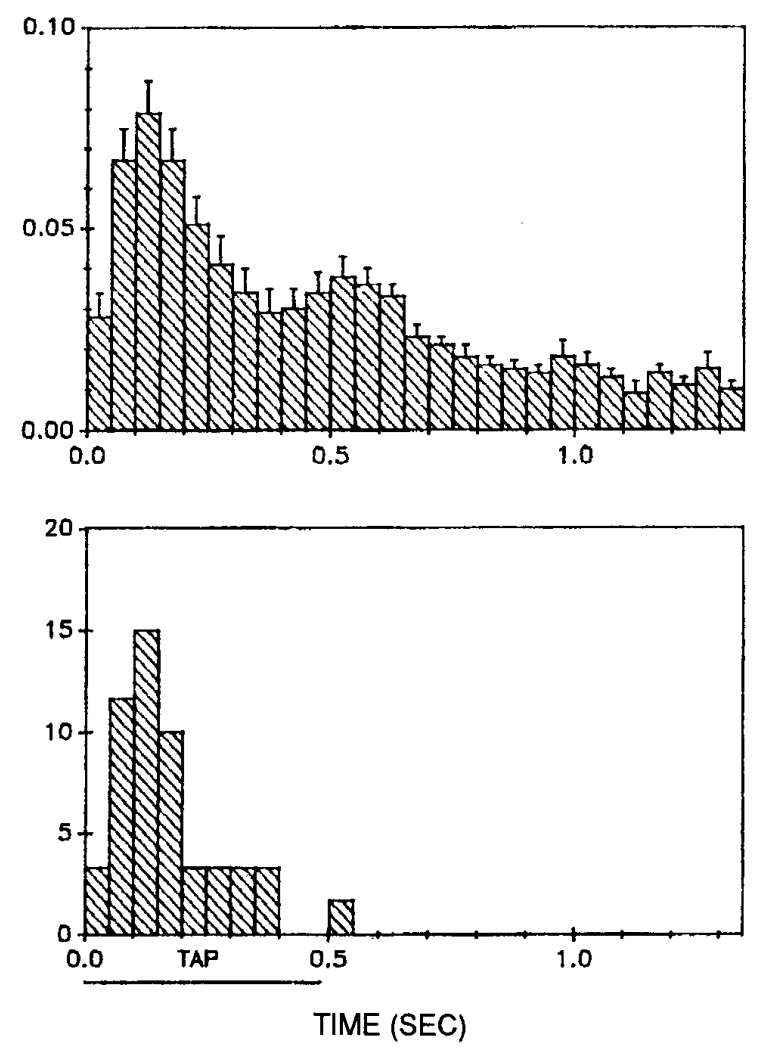

Figure 8. Depression of the complex PSP in a motor neuron but no change in firing of LE sensory neurons during habituation training. $A$, Records from a representative experiment. $B$, Average shape of the complex PSP and pattern of firing of LE cells on trials 1 and 5 in 20 experiments like the one shown in $A$. In some experiments the tap was not within the receptive field of the LE cell, there were problems with the PSP recording in the motor cell, or one cell was lost during habituation, in which case there were data from only one cell. The PSP area in each 50 msec interval has been normalized to the total area on trial 1 in each experiment (the average value on trial 1 was $6658 \mathrm{mVmsec}$ ). The average spike frequency in each $50 \mathrm{msec}$ interval was calculated as the total number of spikes in that interval divided by $(0.05 \times N)$. Time 0.0 for both the PSP and spike frequency histograms is the time that the PSP first exceeded a detection threshold, which did not always include the earliest part of the PSP. The horizontal bar below the $x$-axis represents the approximate duration of the plateau of the tap. 

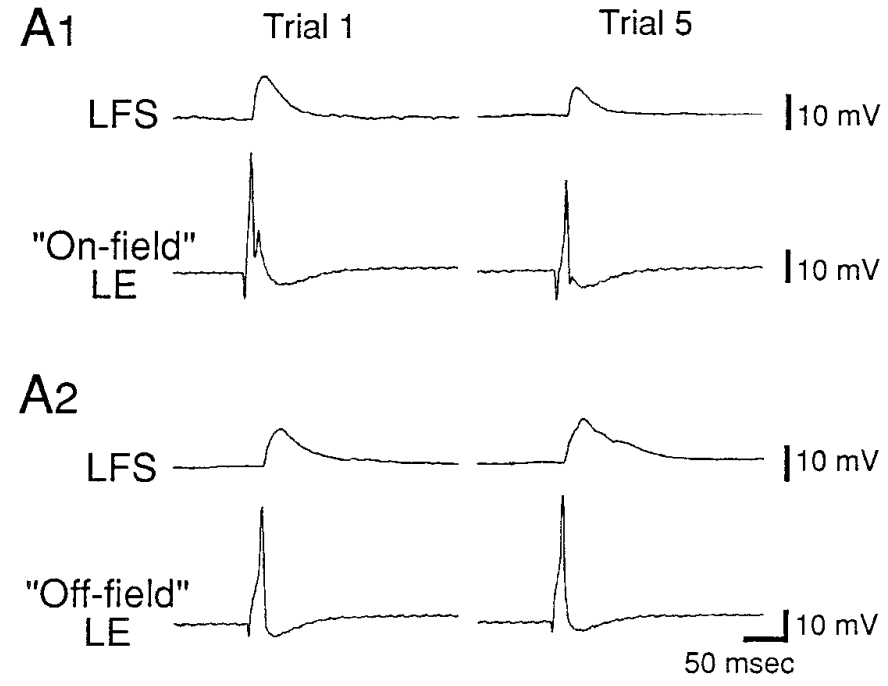

B

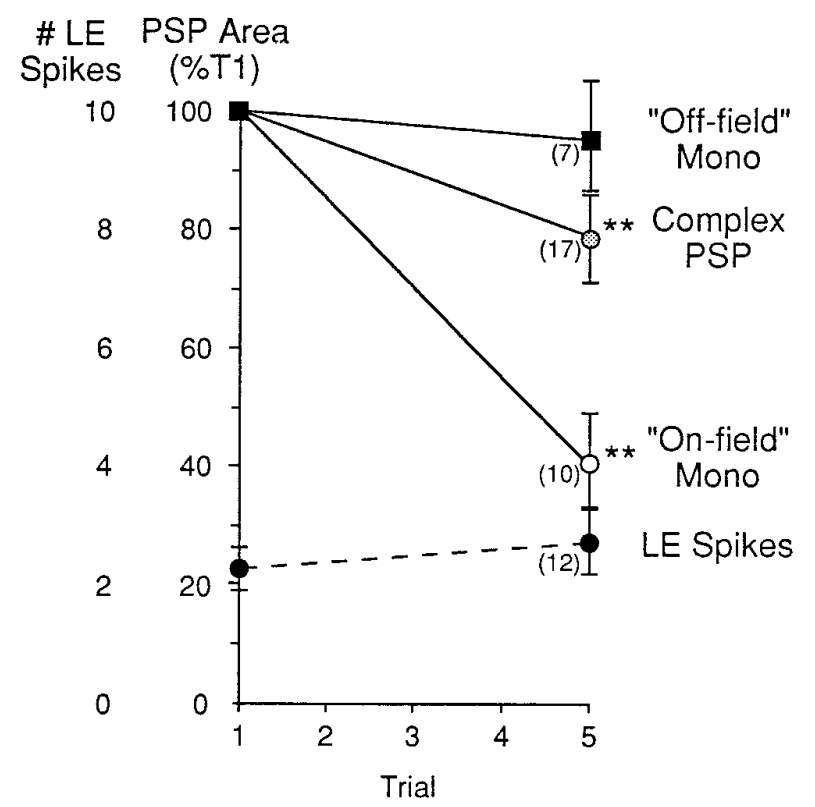

Figure 9. Depression of the monosynaptic PSP from on-field LE sensory neurons during habituation training. $A$, Records from representative experiments. The siphon was stimulated five times at 5 min intervals, and the monosynaptic PSP from an LE neuron was tested shortly before trials 1 and 5. A1, Records from an experiment in which the siphon stimulation was within the receptive field of the LE cell ("On-field"). A2, Records from an experiment in which the siphon stimulation was outside the receptive field of the LE cell ("Off-field"). B, Average results from 17 experiments like the ones shown in $A$, and average results from Figure 8 (area of the complex PSP and number of LE spikes). The average area of the monosynaptic PSP on trial 1 was $352.3 \mathrm{mVmsec}$ for on-field LE cells and 579.6 $\mathrm{mVmsec}$ for off-field LE cells (not significantly different).

PSP does not undergo depression at all (Fig. 8), it evidently includes a component that actually increases during habituation (to offset depression of the monosynaptic PSP). Depression of the monosynaptic PSP could contribute directly to depression of the plateau of the complex PSP during the tap. Because the LE cells do not fire very much after the tap, depression of monosynaptic
PSPs from LE cells could not contribute directly to depression of the later parts of the complex PSP. Depression of the monosynaptic PSP, however, could contribute indirectly if the LE cells excite interneurons that continue to fire after the tap.

\section{Plasticity of monosynaptic PSPs from the unidentified sensory neurons during habituation and dishabituation training}

The results of the experiments illustrated in Figures 1-5 indicate that the LE sensory neurons contribute to the evoked response in the motor neurons in our preparation, but they suggest that other, unidentified sensory neurons also contribute. To examine plasticity of the unidentified sensory neurons during habituation and dishabituation training, we recorded the PSP produced in the motor neuron LDG1 by the solenoid-driven tapper adjusted to not touch the siphon (which we will refer to as water-movement stimulation), which activates the unknown sensory neurons and does not activate the LE sensory neurons (Fig. 1). To ensure that the PSPs were predominantly monosynaptic, we perfused the abdominal ganglion with seawater containing an elevated concentration of $\mathrm{Ca}^{2+}$ and $\mathrm{Mg}^{2+}\left(\mathrm{Hi} \mathrm{Ca}^{2+}, \mathrm{Hi} \mathrm{Mg}^{2+}\right)$, which raises the threshold for spike initiation and blocks most of the polysynaptic component of the PSP by preventing interneurons from firing. The PSP generally had a relatively simple shape with a single peak, consistent with its being predominantly monosynaptic (Figs. $10 A, 11)$. There was significant habituation of the PSP on trial 5 $\left(n=10 ; t_{(9)}=2.79 ; p<0.05\right.$, compared with trial 1$)$ and significant dishabituation on trial 6, 2.5 min after the shock $\left(F_{(1,9)}\right.$ $=10.59 ; p<0.01$, compared with trial 5$)$, which had largely worn off by trial 7, $12.5 \mathrm{~min}$ after the shock (Fig. 10B). Dishabituation of the PSP was significantly greater $2.5 \mathrm{~min}$ than $12.5 \mathrm{~min}$ after the shock $\left(F_{(1,9)}=6.25 ; p<0.05\right)$. There were no obvious changes in the shape of the PSP during habituation and dishabituation training (Fig. 11).

We also examined the effects of serotonin (5-HT) on the PSP produced by water-movement stimulation of the siphon. We used the same dishabituation procedure as in the previous experiments, except that instead of shocking the mantle we began perfusing the abdominal ganglion with $10 \mu \mathrm{M}$ 5-HT 2.5 min after trial 5. As illustrated in Figure 12, there was little dishabituation of the PSP on trial 6, $2.5 \mathrm{~min}$ after the beginning of perfusion with 5-HT, but there was significant dishabituation of the PSP on trial 7, $12.5 \mathrm{~min}$ after the beginning of 5 -HT perfusion $\left(n=9 ; F_{(1,8)}=10.79 ; p<\right.$ 0.05 , compared with trial 5). Dishabituation of the PSP was significantly greater $12.5 \mathrm{~min}$ than $2.5 \mathrm{~min}$ after the start of perfusion with 5 -HT $\left(F_{(1,8)}=5.32 ; p<0.05\right)$, which is the reverse of the results with mantle shock. As with dishabituation by mantle shock, there was no obvious change in the shape of the PSP during dishabituation by 5-HT (Fig. 13).

\section{DISCUSSION}

\section{Participation of LE and unidentified siphon sensory neurons in the evoked response in the motor neurons}

Byrne et al. (1974, 1978a,b) first characterized the response of the LE siphon sensory neurons to controlled-force stimulation of the siphon, and argued that the LE cells account for most of the response in the motor neuron. Our results replicate those of Byrne et al. (1974, 1978a) in several ways. We found that the average threshold for producing an action potential in an LE neuron is $\sim 4 \mathrm{gm} / \mathrm{mm}^{2}$ (Fig. $3 C$ ), that the number of action potentials produced is a monotonic function of stimulus intensity 


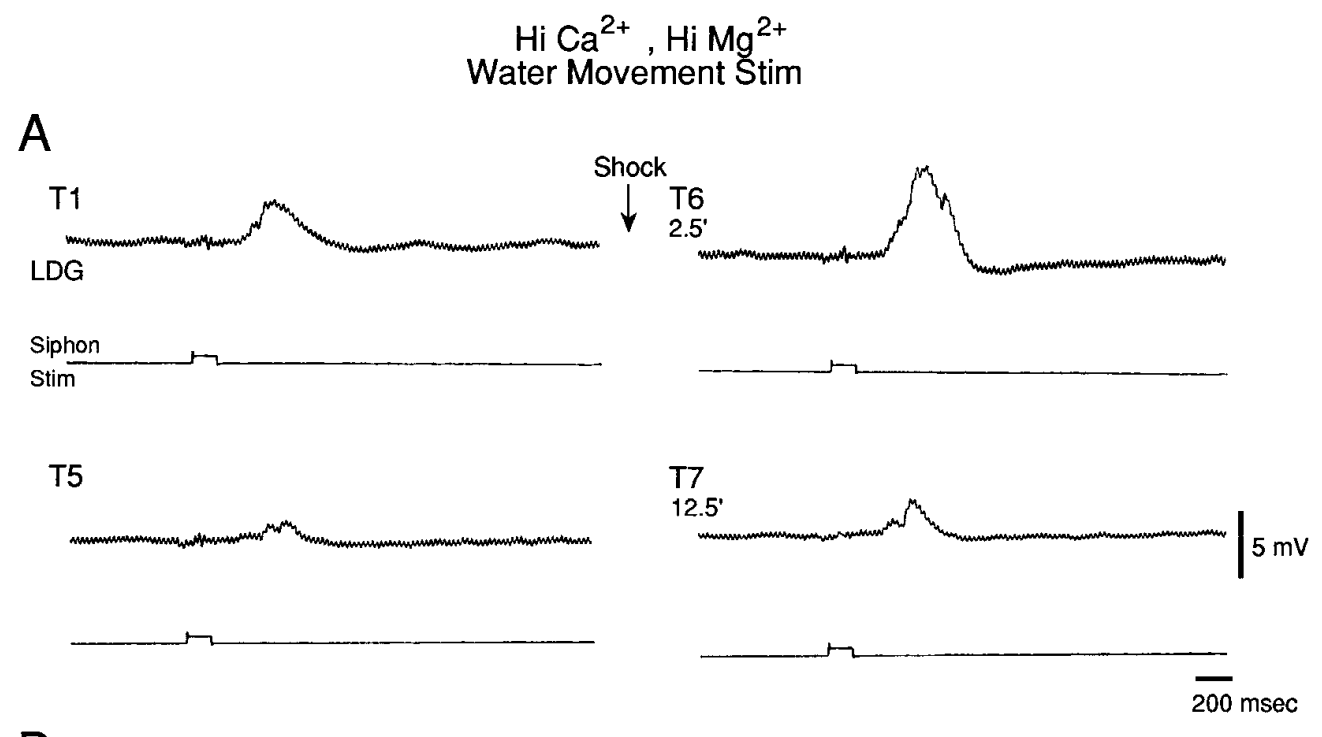

Figure 10. The monosynaptic component of the PSP produced in the gill motor neuron LDG1 by watermovement stimulation of the siphon during habituation and dishabituation training. The abdominal ganglion was perfused with seawater containing elevated concentrations of $\mathrm{Ca}^{2+}$ and $\mathrm{Mg}^{2+}$, which blocks most of the polysynaptic component of the PSP. $A$, Records from a representative experiment showing the PSP in $\mathrm{Hi} \mathrm{Ca}{ }^{2+}, \mathrm{Hi}$ $\mathrm{Mg}^{2+}$ seawater during habituation and dishabituation. $B$, Average results from 10 experiments like the one shown in $A$. The area under the PSP was measured during the first $1.4 \mathrm{sec}$ after the start of the PSP and was normalized to the value on trial 1 in each experiment (the average value on trial 1 was 3690 $\mathrm{mVmsec}$ ).

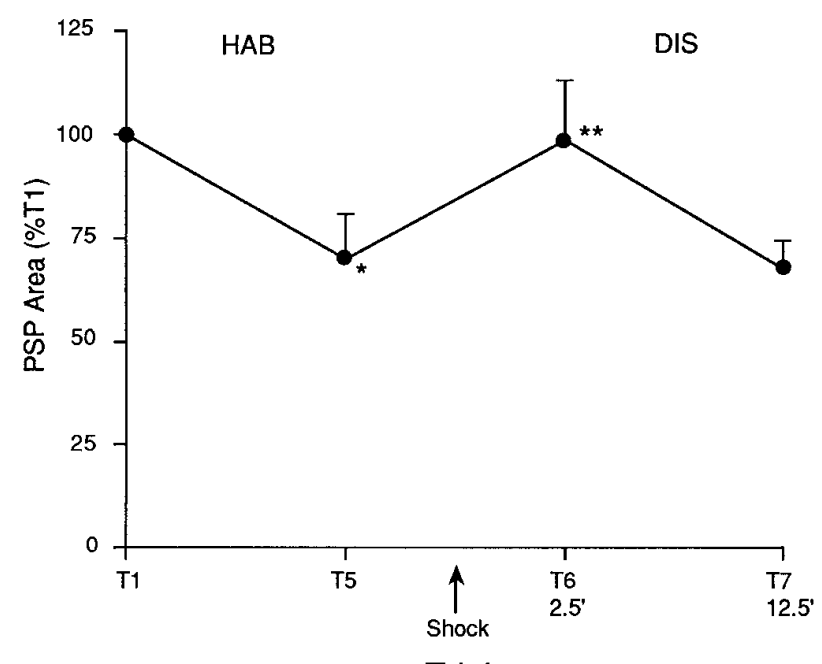

with a smaller slope above $10 \mathrm{gm} / \mathrm{mm}^{2}$ (Fig. $5 B 1$ ), and that the number of action potentials does not decrease with repeated stimulation (Fig. 5B2). Our results, however, extend those of Byrne et al. (1978b) in several ways regarding the contribution of the LE cells to the response produced in a motor neuron by stimulation of the siphon. First, we found that the LE cells have higher thresholds than the motor neurons (Fig. $3 C$ ), which respond to weak water-movement stimuli that never fire the LE cells (Figs. 1, 3). Second, we found that the onset of the PSP always precedes the first spike in an LE neuron (Figs. 2-4, 5A) and that the peak of the response in the motor neurons precedes the peak in the LE neurons by $\sim 50 \mathrm{msec}$ (Fig. 6). Third, we found that firing of the LE neurons stopped $\sim 250 \mathrm{msec}$ after the end of the tap, but firing of the motor neurons continued for $>500 \mathrm{msec}$ (Fig. 6). Byrne et al. (1978b) acknowledged the possibility that the LE cells did not account for all of the response in the motor neuron, but focused on the apparently large contribution of the LE cells.

Our results indicate that firing of LE cells contributes to the major part of the response in the motor cells during and immediately after a siphon tap (Figs. 6, 8). In addition, the late response in the motor cells could be attributable to firing of interneurons that are excited by the LE cells; however, both the earliest response in the motor cells and the response to very weak stimuli (such as water movements) cannot be accounted for by firing of LE cells. These results therefore suggest that other sensory neurons with shorter latencies and lower thresholds also contribute to the response. Like the LE cells, the pleural sensory cells have latencies that are longer than the onset of the PSP in motor neurons (Walters et al., 1983a). All of the other identified mechanosensory neurons in Aplysia whose response properties have been investigated also have thresholds that are similar to those of the LE cells, and none are known to respond to weak watermovement stimuli (Byrne et al., 1974; Rosen et al., 1979; Byrne, 1980; Fiore and Geppetti, 1981; Walters et al., 1983a; Weiss et al., 1986; Dubuc and Castellucci, 1991; Miller et al., 1994). Shortlatency, low-threshold sensory neurons therefore have evidently not yet been identified in Aplysia.

\section{Properties of the unidentified siphon sensory neurons}

There are several questions regarding the expected properties of the unidentified sensory neurons. First, do they simply have lower 

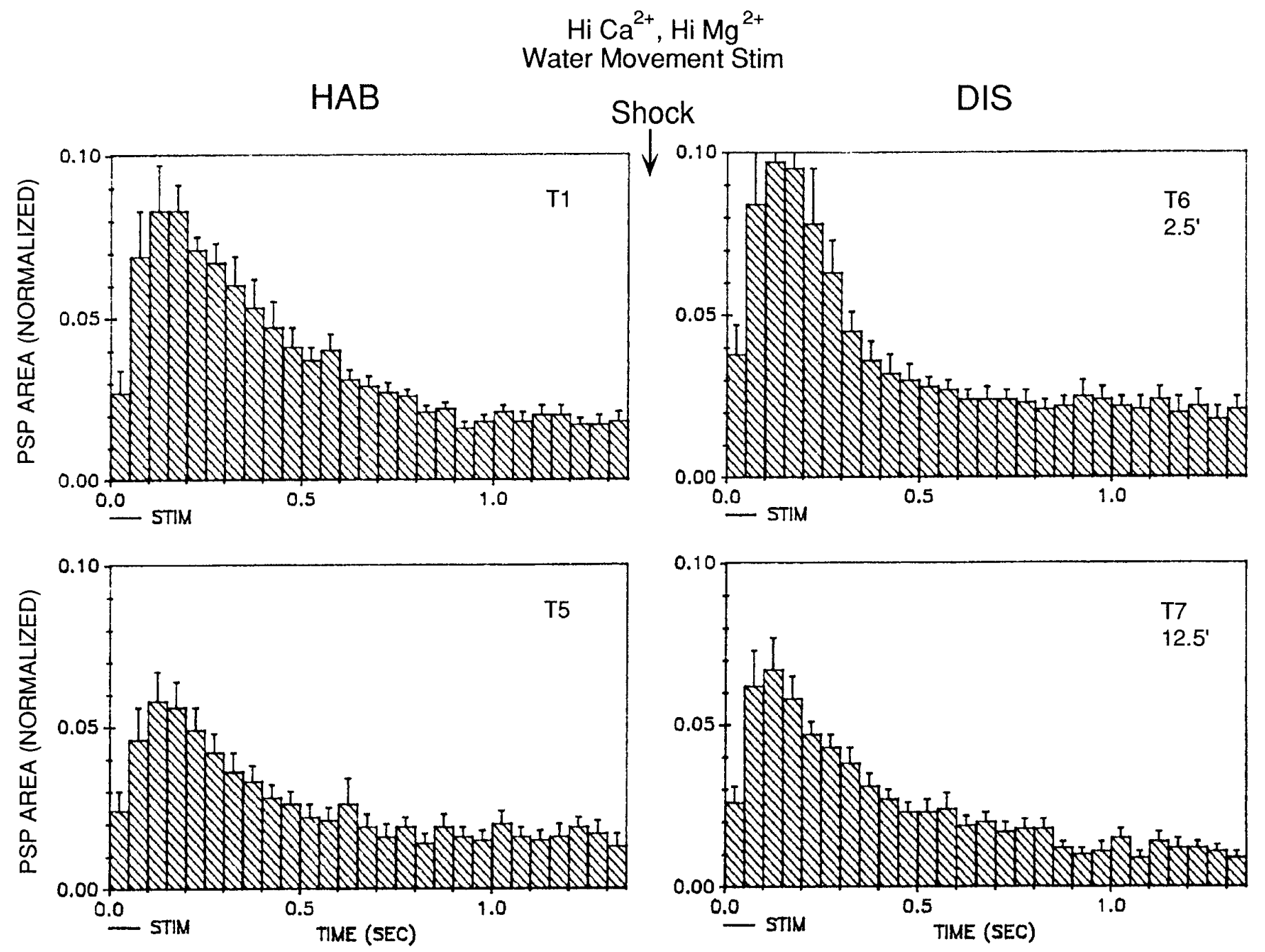

Figure 11. Average shape of the complex PSP produced in LDG1 by water-movement stimulation of the siphon during habituation and dishabituation by mantle shock in the same experiments as in Figure $10 \mathrm{~B}$. The PSP area in each $50 \mathrm{msec}$ interval has been normalized to the total area on trial 1 in each experiment. The horizontal bar below the $x$-axis indicates the approximate duration of the water-movement stimulation.

thresholds than the LE cells, or do they respond to a different modality such as vibration? Two types of nerve endings have been described in the skin of the tail and siphon of Aplysia: ciliated endings at the epidermal surface that stain with antibodies to class III $\beta$-tubulin (Steffensen et al., 1993), and spindle-like structures in the muscle layer that stain with antibodies to sensorin (Steffensen and Morris, 1996). Because the LE cells and most of the other known mechanosensory neurons also stain with antibodies to sensorin (Brunet et al., 1991), it seems possible that the ciliated endings belong to another class of sensory neurons that respond to different types of stimuli.

Second, are the cell bodies of the unknown mechanosensory neurons located in the CNS, like the identified mechanosensory neurons, or in the periphery, like chemosensory neurons in Aplysia (Emery and Audesirk, 1978)? Steffensen et al. (1993) did not observe any neuronal cell bodies in the skin of the tail or siphon, although there are cell bodies along the siphon nerve (Bailey et al., 1979), and autoradiographic evidence suggests that there may be a projection from peripheral sensory cells to the abdominal ganglion (Xin et al., 1995). The shorter latency of the unknown sensory cells suggests a faster conduction velocity, which is nor- mally associated with a thicker axon and a larger cell body. Because no large cell bodies have been reported in the periphery, this result suggests a central location. Alternatively, a shorter latency might result from a faster generator potential, which could be consistent with either a central or a peripheral location of the cell bodies. The observation that the difference in latencies is not affected by stimulus intensity (Fig. $5 A$ ), however, suggests that it may not be attributable to a difference in the rise time of the generator potential.

Finally, do the unknown sensory cells have synaptic plasticity that is similar to the LE cells? The LE sensory neurons undergo homosynaptic depression and heterosynaptic facilitation that are thought to contribute to habituation and dishabituation (Castellucci et al., 1970), and most of the other identified mechanosensory neurons in Aplysia have similar synaptic plasticity (Fiore and Meunier, 1979; Rosen et al., 1979, 1989; Byrne, 1980; Walters et al., 1983a,b; Dubuc and Castellucci, 1991). When the ganglion was perfused with $\mathrm{Hi} \mathrm{Ca}^{2+}$, $\mathrm{Hi} \mathrm{Mg}^{2+}$ seawater, the PSPs produced by controlled force stimulation of the siphon (Cohen et al., 1997, their Fig. 11) and water-movement stimulation (our Fig. 10) underwent similar depression and facilitation during habituation 


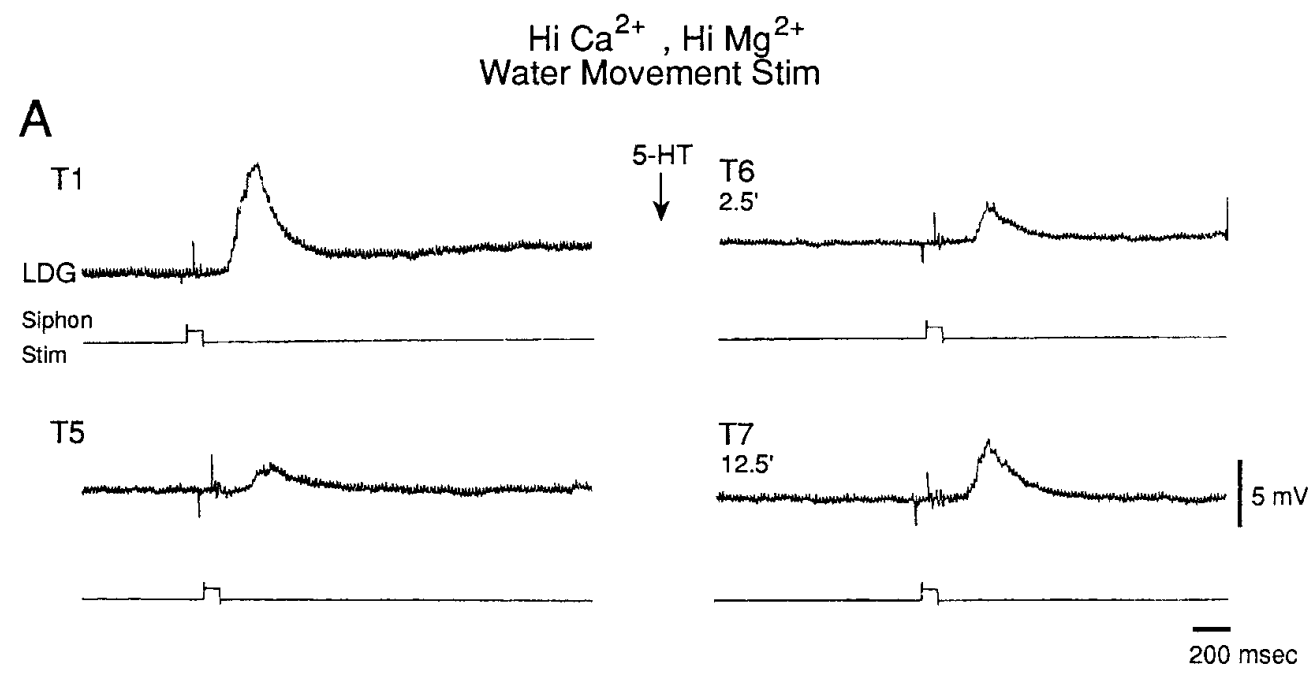

Figure 12. Serotonin facilitates the PSP produced in LDG1 by watermovement stimulation of the siphon. For details, see Figure 10 legend. Perfusion of the abdominal ganglion with $10 \mu \mathrm{M}$ serotonin began $2.5 \mathrm{~min}$ after trial 5 and continued for the rest of the experiment $(n=9)$. The average value on trial 1 was $5157 \mathrm{mVmsec}$.

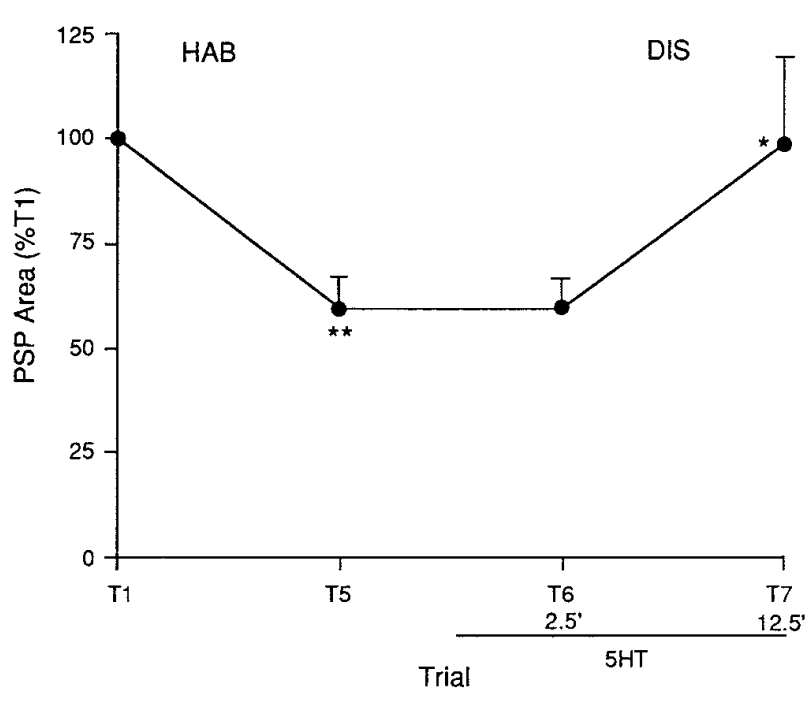

and dishabituation training, suggesting that monosynaptic PSPs from the LE sensory neurons and the unidentified sensory neurons also have similar plasticity during these simple forms of learning. As an additional comparison, we examined the effect of serotonin on the PSP produced by water-movement stimulation of the siphon. Serotonin produces facilitation of PSPs from LE sensory neurons and most, but not all, of the other identified mechanosensory neurons in Aplysia (Brunelli et al., 1976; Walters et al., 1983b; Rosen et al., 1989; Dubuc and Castellucci, 1991). Serotonin also produced facilitation of PSPs from the unidentified sensory neurons in these experiments (Fig. 12), demonstrating another similarity in plastic properties of the two types of sensory neurons. These results suggest that in several aspects of plasticity the LE sensory neurons are representative of the entire siphon sensory neuron population.

The facilitation by serotonin (Fig. 12) was somewhat slow to develop, compared with facilitation by mantle shock (Fig. 10). One possible explanation for this discrepancy is that access of serotonin to the synapses is slow; however, serotonin and cAMP produced rapid facilitation of PSPs from LE sensory neurons in similar experiments (Brunelli et al., 1976; Fitzgerald and Carew, 1991; Trudeau and Castellucci, 1992). Therefore these results suggest either that the synapses of the unidentified sensory neurons are less accessible or that serotonin might produce facilitation of the unidentified sensory neurons by a different second messenger (perhaps acting through protein kinase $\mathrm{C}$, which produces relatively slow facilitation of the LE sensory neurons) (Ghirardi et al., 1992; Sugita et al., 1992). If so, the rapid facilitation of PSPs from unidentified sensory neurons by mantle shock (Fig. 10) might be mediated predominantly by a different modulatory transmitter, such as SCP or the L29 transmitter, both of which produce rapid facilitation of PSPs from LE sensory neurons (Hawkins et al., 1981; Abrams et al., 1984). Additional experiments will be necessary to test these possibilities.

\section{Contribution of monosynaptic PSPs from LE sensory neurons to the motor neuron response}

The inferred existence of a second class of siphon sensory neurons raises the question of the quantitative contribution of the LE sensory neurons. Previous estimates of the contribution of monosynaptic PSPs from LE sensory neurons to the motor neuron response have ranged from $>50 \%$ (Byrne et al., 1978b) to $<10 \%$ (Hickie et al., 1995). Our results provide a possible 


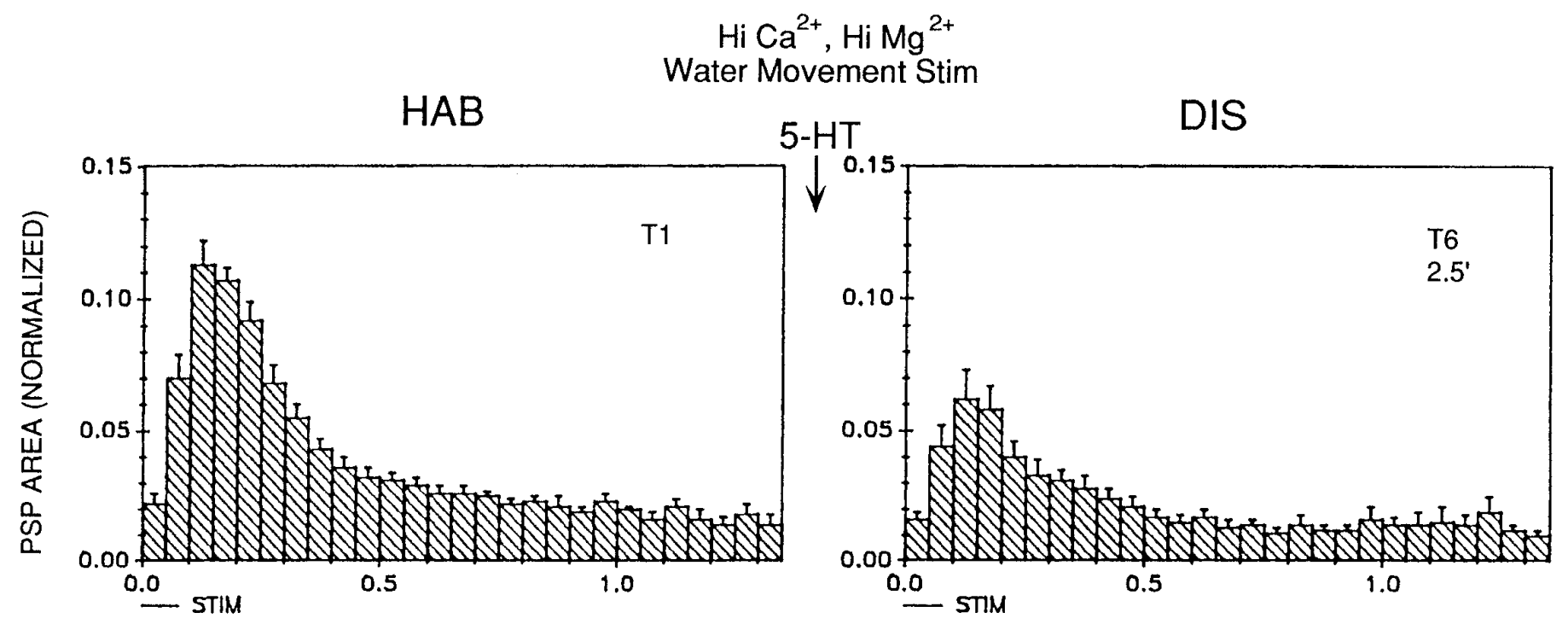

$\mathrm{Hi} \mathrm{Ca}{ }^{2+}, \mathrm{Hi} \mathrm{Mg}^{2+}$

Water Movement Stim
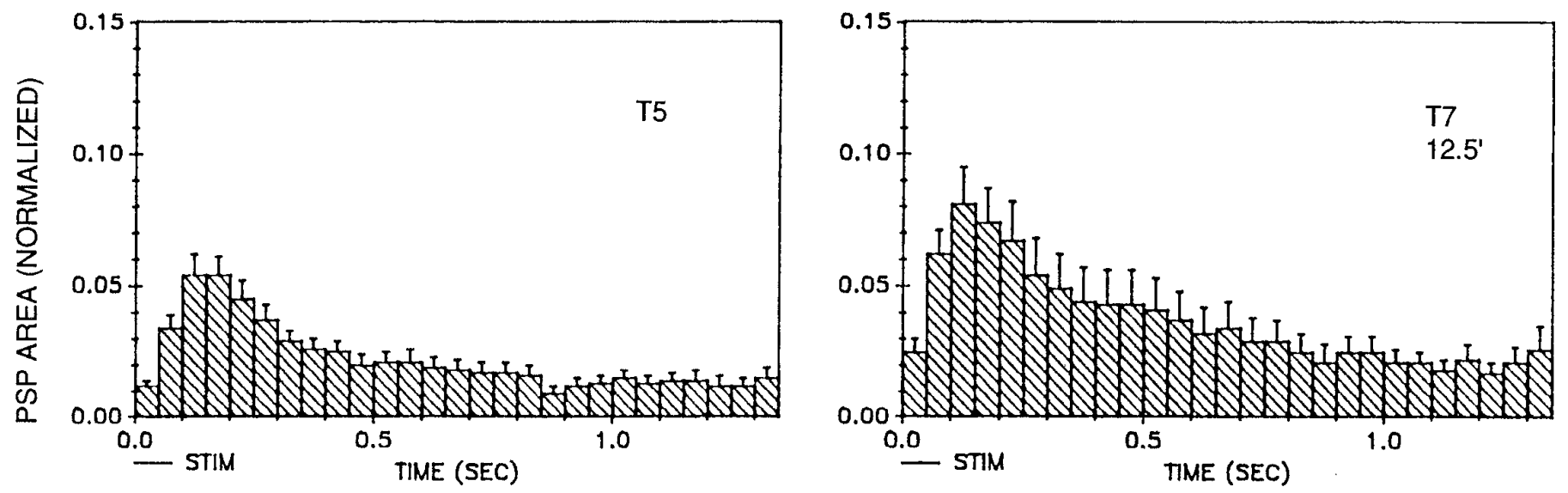

Figure 13. Average shape of the complex PSP produced in LDG1 by water-movement stimulation of the siphon during habituation and dishabituation by serotonin in the same experiments as in Figure $12 B$.

explanation for some of these discrepancies. With a very weak, brief stimulus to the siphon, the LE cells may not contribute at all (Figs. 1, 3); however, with the moderate intensity stimulus of $500 \mathrm{msec}$ duration that we have used in behavioral experiments with this preparation (Cohen et al., 1991, 1997; Hawkins et al., 1993), the LE cells make a substantial contribution. They fire several spikes (Fig. 5) that occur during the major part of the motor neuron response (Figs. 6, 8). On average, the monosynaptic PSP produced by a single spike in an LE neuron is $35.2 \%$ of the amplitude and $6.4 \%$ of the area of the complex PSP produced by siphon stimulation (Fig. 7). This estimate agrees reasonably well with the results of similar experiments by Byrne et al. (1978b). By multiplying 6.4\% and 2.8, the average number of spikes produced in an LE cell by siphon stimulation in these experiments (Fig. 9), the monosynaptic PSPs from a single LE cell could contribute as much as $18 \%$ of the area of the complex PSP. The results of Byrne et al. (1974) indicate that a similar stimulus causes approximately eight LE cells to fire, suggesting that the total contribution from the LE cells could be $>100 \%$. Clearly this is an overestimate, probably because the monosynaptic PSPs from the LE cells do not add linearly. An upper limit is provided by the total contribution of monosynaptic PSPs from all sensory neurons (LE and unidentified), which has been estimated to be between $21 \%$ (Cohen et al., 1997) or $25 \%$ (Trudeau and Castellucci, 1992) and 58\% (Byrne et al., 1978b). Comparison of the contribution of a single LE cell and the total contribution of all sensory neurons suggests that the LE cells probably contribute most of the total sensory input to the motor neurons under our experimental conditions.

\section{Contribution of homosynaptic depression of monosynaptic PSPs to habituation of the motor neuron response}

Previous studies have suggested that homosynaptic depression of monosynaptic PSPs from LE sensory neurons is a major mechanism of habituation of the reflex response. These studies have shown that repetitive low frequency firing of an LE cell produces depression of the monosynaptic PSP (Castellucci et al., 1970) that parallels depression of the complex PSP produced by repetitive siphon stimulation (Byrne et al., 1978b). This depression occurs even with the 5 min interstimulus interval that we have used in our behavioral experiments (Cohen et al., 1991, 1997; Hawkins et al., 1993) at synapses both in the ganglion (Carew et al., 1984) and in isolated cell culture (Eliot et al., 1994), indicating that it is intrinsic to the sensory neuron- 
motor neuron synapses. Furthermore, monosynaptic PSPs from the unidentified sensory neurons also undergo similar depression (Figs. 10, 12).

Most of the previous studies did not examine monosynaptic PSPs during behavioral training; however, results from two studies that did have suggested that mechanisms other than homosynaptic depression may contribute to habituation of reflex responses in Aplysia. First, Goldberg and Lukowiak (1984) reported that repetitive siphon stimulation produces depression of monosynaptic PSPs from both on-field and offfield LE cells, suggesting that heterosynaptic inhibition of monosynaptic PSPs contributes to habituation. In similar experiments, however, we did not observe depression of PSPs from off-field LE cells (Fig. 9). Second, Stopfer and Carew (1996) reported that repetitive tail stimulation that produces habituation of the response in tail motor neurons also produces facilitation of monosynaptic PSPs from both on-field and offfield tail sensory neurons, suggesting that plasticity in interneurons contributes to habituation. In similar experiments, however, we observed depression of PSPs from on-field LE cells (Fig. 9). It is not clear why we obtained different results in these experiments. Two procedural differences were that we used a longer interstimulus interval and recorded the responses in different motor neurons. In any case, our results support the idea that homosynaptic depression of monosynaptic PSPs from siphon sensory neurons is a major mechanism of habituation in our preparation. It should now be possible to perform similar analyses of the mechanisms of dishabituation, sensitization, and classical conditioning in this preparation.

\section{REFERENCES}

Abrams TW, Castellucci VF, Camardo JS, Kandel ER, Lloyd PE (1984) Two endogenous neuropeptides modulate the gill and siphon withdrawal reflex in Aplysia by means of presynaptic facilitation involving cAMP-dependent closure of a serotonin-sensitive potassium channel. Proc Natl Acad Sci USA 81:7956-7960.

Bailey CH, Castellucci VF, Koester J, Kandel ER (1979) Cellular studies of peripheral neurons in siphon skin of Aplysia californica. J Neurophysiol 42:530-557.

Brunelli M, Castellucci V, Kandel ER (1976) Synaptic facilitation and behavioral sensitization in Aplysia: possible role of serotonin and cyclic AMP. Science 194:1178-1181.

Brunet JF, Shapiro E, Foster SA, Kandel ER, Iino Y (1991) Identification of a peptide specific for Aplysia sensory neurons by PCR-based differential screening. Science 252:856-859.

Byrne JH (1980) Neural circuit for inking behavior in Aplysia californica. J Neurophysiol 43:896-911.

Byrne JH, Castellucci VF, Kandel ER (1974) Receptive fields and response properties of mechanoreceptor neurons innervating siphon skin and mantle shelf of Aplysia. J Neurophysiol 37:1041-1064.

Byrne JH, Castellucci VF, Carew TJ, Kandel ER (1978a) Stimulusresponse relations and stability of mechanoreceptor and motor neurons mediating defensive gill-withdrawal reflex in Aplysia. J Neurophysiol 41:402-417.

Byrne JH, Castellucci VF, Kandel ER (1978b) Contribution of individual mechanoreceptor sensory neurons to defensive gill-withdrawal reflex in Aplysia. J Neurophysiol 41:418-431.

Carew TJ, Hawkins RD, Abrams TW, Kandel ER (1984) A test of Hebb's postulate at identified synapses which mediate classical conditioning in Aplysia. J Neurosci 4:1217-1224.

Castellucci VF, Kandel ER (1974) A quantal analysis of the synaptic depression underlying habituation of the gill-withdrawal reflex in Aplysia. Proc Natl Acad Sci USA 71:5004-5008.

Castellucci VF, Kandel ER (1976) Presynaptic facilitation as a mechanism for behavioral sensitization in Aplysia. Science 194:1176-1178.

Castellucci VF, Pinsker H, Kupfermann I, Kandel ER (1970) Neuronal mechanisms of habituation and dishabituation of the gill-withdrawal reflex in Aplysia. Science 167:1745-1748.
Cohen TE, Henzi V, Kandel ER, Hawkins RD (1991) Further behavioral and cellular studies of dishabituation and sensitization in Aplysia. Soc Neurosci Abstr 17:1302.

Cohen TE, Kaplan SW, Kandel ER, Hawkins RD (1997) A simplified preparation for relating cellular events to behavior: mechanisms contributing to habituation, dishabituation, and sensitization of the Aplysia gill-withdrawal reflex. J Neurosci 17:2887-2900.

Dubuc B, Castellucci VF (1991) Receptive fields and properties of a new cluster of mechanoreceptor neurons innervating the mantle region and the branchial cavity of the marine mollusk Aplysia californica. J Exp Biol 156:315-334.

Eliot LS, Kandel ER, Hawkins RD (1994) Modulation of spontaneous transmitter release during depression and post-tetanic potentiation of Aplysia sensory-motor neuron synapses in culture. J Neurosci 14: 3280-3292.

Emery DG, Audesirk TE (1978) Sensory cells in Aplysia. J Neurobiol 9:173-179.

Fiore L, Geppetti L (1981) Neural control of buccal mass activity in Aplysia. In: Advances in physiological sciences, Vol 23. Neurobiology of invertebrates (Salanki J, ed), pp 201-223. New York: Pergamon.

Fiore L, Meunier JM (1979) Synaptic connections and functional organization in Aplysia buccal ganglia. J Neurobiol 110:13-29.

Fitzgerald K, Carew TJ (1991) Serotonin mimics tail shock in producing transient inhibition in the siphon withdrawal reflex of Aplysia. J Neurosci 11:2510-2528.

Frazier WT, Kandel ER, Kupfermann I, Waziri R, Coggeshall RE (1967) Morphological and functional properties of identified neurons in the abdominal ganglion of Aplysia californica. J Neurophysiol 30:1288-1351.

Frost WN, Clark GA, Kandel ER (1988) Parallel processing of shortterm memory for sensitization in Aplysia. J Neurobiol 19:297-334.

Ghirardi M, Braha O, Hochner B, Montarolo PG, Kandel ER, Dale N (1992) Roles of PKA and PKC in facilitation of evoked and spontaneous transmitter release at depressed and nondepressed synapses in Aplysia sensory neurons. Neuron 9:479-489.

Goldberg JI, Lukowiak K (1984) Transfer of habituation in Aplysia: contribution of heterosynaptic pathways in habituation of the gillwithdrawal reflex. J Neurobiol 15:395-411.

Hawkins RD, Frost L (1995) Contribution of LE siphon sensory neurons to habituation, dishabituation, and sensitization of the gill-withdrawal reflex in Aplysia. Soc Neurosci Abstr 21:1024.

Hawkins RD, Castellucci VF, Kandel ER (1981) Interneurons involved in mediation and modulation of gill-withdrawal reflex in Aplysia. II. Identified neurons produce heterosynaptic facilitation contributing to behavioral sensitization. J Neurophysiol 45:315-326.

Hawkins RD, Greene W, Kandel ER (1993) Classical conditioning, differential conditioning, and second-order conditioning of the Aplysia gill-withdrawal reflex in an isolated mantle organ preparation. Soc Neurosci Abstr 19:17.

Hickie C, Cohen LB, Balaban PM (1995) Voltage-sensitive dye recording from the Aplysia abdominal ganglion indicates modest LE cell response to a light siphon touch. Soc Neurosci Abstr 21:1679.

Kaplan SW, Kandel ER, Hawkins RD (1993) Plasticity in the monosynaptic component of the Aplysia gill-withdrawal reflex during habituation, dishabituation, and sensitization. Soc Neurosci Abstr 19:16.

Kaplan SW, Kandel ER, Hawkins RD (1994) Plasticity of LE and non-LE siphon sensory neurons during habituation and dishabituation of the Aplysia gill-withdrawal reflex. Soc Neurosci Abstr 20:1073.

Kupfermann I, Carew TJ, Kandel ER (1974) Local, reflex, and central commands controlling gill and siphon movements in Aplysia. J Neurophysiol 37:996-1019.

Miller MW, Rosen SC, Schissel SL, Cropper EC, Kupfermann I, Weiss KR (1994) A population of SCP-containing neurons in the buccal ganglion of Aplysia are radula mechanoafferents and receive excitation of central origin. J Neurosci 14:7008-7023.

Rosen SC, Susswein AJ, Cropper EC, Weiss KR, Kupfermann I (1989) Selective modulation of spike duration by serotonin and the neuropeptides, FMRFamide, $\mathrm{SCP}_{\mathrm{B}}$, buccalin and myomodulin in different classes of mechanoafferent neurons in the cerebral ganglion of Aplysia. J Neurosci 9:390-402.

Rosen SC, Weiss KR, Kupfermann I (1979) Response properties and synaptic connections of mechanoafferent neurons in cerebral ganglion of Aplysia. J Neurophysiol 42:954-974.

Steffensen I, Morris CE (1996) Coiled mechanoreceptors in Aplysia revealed by sensorin immunofluorescence and confocal microscopy. Invest Neurosci 2:129-134. 
Steffensen I, Anctil M, Morris CE (1993) Neural structures in the receptive field of pleural ganglion mechanosensory neurons of Aplysia californica. Cell Tissue Res 273:487-497.

Stopfer M, Carew TJ (1996) Heterosynaptic facilitation of tail sensory neuron synaptic transmission during habituation in tail-induced tail and siphon withdrawal reflexes of Aplysia. J Neurosci 16:4933-4948.

Sugita S, Goldsmith JR, Baxter DA, Byrne JH (1992) Involvement of protein kinase $\mathrm{C}$ in serotonin-induced spike broadening and synaptic facilitation in sensorimotor connections of Aplysia. J Neurophysiol 68:643-651.

Trudeau L-E, Castellucci VF (1992) Contribution of polysynaptic pathways in the mediation and plasticity of the Aplysia gill and siphon withdrawal reflex: evidence for differential modulation. J Neurosci 12:3838-3848.

Walters ET, Byrne JH, Carew TJ, Kandel ER (1983a) Mechanoafferent neurons innervating tail of Aplysia. I. Response properties and synaptic connections. J Neurophysiol 50:1522-1542.

Walters ET, Byrne JH, Carew TJ, Kandel ER (1983b) Mechanoafferent neurons innervating tail of Aplysia. II. Modulation by sensitizing stimuli. J Neurophysiol 50:1543-1559.

Weiss KR, Chiel HJ, Kupfermann I (1986) Sensory function and gating of histaminergic neuron C2 in Aplysia. J Neurosci 6:2416-2426.

Xin Y, Weiss KR, Kupfermann I (1995) Distribution in the central nervous system of Aplysia of afferent fibers arising from cell bodies located in the periphery. J Comp Neurol 359:627-643. 